\title{
Developing a service-learning module for oral health:
}

\section{A needs assessment}

\author{
R Ebrahim, ${ }^{1} \mathrm{MSc}$ (Dent); H Julie, ${ }^{2} \mathrm{MPH}, \mathrm{MCur}, \mathrm{PhD}$ \\ ${ }^{1}$ Extended Programme, Faculty of Natural and Agricultural Sciences, University of Pretoria, South Africa \\ ${ }^{2}$ School of Nursing, Faculty of Community and Health Sciences, University of the Western Cape, Cape Town, South Africa
}

Corresponding author: R Ebrahim (ruebecca.ebrahim@up.ac.za)

Background. Service learning (SL) as a pedagogy in higher education must be differentiated from other services with a primarily philanthropic intent. Dental therapy and oral hygiene students at Sefako Makgatho Health Sciences University, School of Oral Health Sciences, Pretoria, South Africa visit community sites during their 2nd year of study. However, the current curricula would need restructuring for alignment with the espoused pedagogy and standards of SL. Such an SL curriculum design would thus allow for the provision of meaningful services to communities as an integral component of these programmes.

Objective. To explore (i) perceptions of 2nd-year oral health students; and (ii) opinions of academics with regard to the need for an SL module. Methods. Purposive sampling was used to conduct two focus group discussions with academics involved in curriculum development $(n=11)$ and students who had previous exposure to communities $(n=10)$. A survey containing open-ended questions was completed by 9 academics, who would implement the proposed SL module. Frequencies were calculated and data from the open questions were analysed for emergent themes.

Results. Most academics $(89 \%, n=8)$ indicated that working effectively with others as members of a team and developing cultural sensitivity were achievable from an SL module. Two themes emerged from the focus groups, i.e. (i) enhanced teaching and learning - students could apply theoretical and clinical training in an authentic setting; and (ii) standardisation of training - an SL module would ensure consistency when engaging with communities.

Conclusion. The needs assessment was valuable to inform the development and implementation of the SL module.

Afr J Health Professions Educ 2017;9(1):13-16. DOI:10.7196/AJHPE.2017.v9i1.597

Proponents of service learning (SL) state that it is a form of experiential education that combines student learning goals intentionally with service provision to communities. ${ }^{[1-4]}$ The rationale for these SL activities is grounded in educational philosophies that propagate social responsibility as the primary goal of learning. ${ }^{[5]}$ Educators who integrate SL into the curriculum hope to develop cultural sensitivity and civic responsibility in students by raising student awareness with regard to the challenges communities experience. This philosophical stance is also reflected in SL definitions formulated by acclaimed US scholars, such as Bringle and Hatcher, ${ }^{[2]}$ and in South African (SA) higher education policy documents.

Bringle and Hatcher ${ }^{[2]}$ define SL as a 'course-based, credit-bearing educational experience in which students participate in an organised service activity that meets the identified community needs and reflect on the service activity in such a way to gain further understanding of the course content, a broader appreciation of the discipline and an enhanced sense of personal values and civic responsibility?

In the SA context, the Higher Education Quality Committee (HEQC) positioned SL as a core function of higher education to advance social development and transformation of disadvantaged communities. ${ }^{[3]}$ To this end, the HEQC has formulated criteria for SL as Criterion 7 in the Framework for Institutional Audits ${ }^{[6]}$ and in the Framework for Programme Accreditation. ${ }^{[7]}$

In addition, SL provides an opportunity for the students to reflect on the service activity in such a way as to gain further understanding of the course content, a broader appreciation of the discipline, and an enhanced sense of civic responsibility. This is achieved through the introduction of reflection as an assessment strategy. According to Elyer and Giles, ${ }^{[8]}$ reflection has been identified as a foundational principle of SL and is regarded as the glue that holds service and learning together to provide an optimal educative experience.

Reflective practice is about acquiring the skills and attitude to inquire continually into one's own professional practice and into the context in which it is embedded. It can also take place on different levels to which students are exposed in academic practices. Bringle and Hatcher, as cited by Julie et al. ${ }^{[9]}$ state that SL provides higher education institutions with a strategy to explore ways of incorporating service to extend their mission, enhance student achievement, and engage students in their communities as part of their academic curriculum.

\section{Problem statement}

Students of Dental Therapy and Oral Hygiene, School of Oral Health Sciences, Sefako Makgatho Health Sciences University (formerly University of Limpopo, Medunsa Campus), Pretoria, SA are trained in predominantly clinical settings. However, these clinical placements are not linked to learning outcomes aimed at developing social responsiveness in the students. Likewise, the community site visits for 2nd-year students are not explicitly linked to their learning outcomes - these visits tend to happen randomly. 


\section{Why a needs assessment?}

For SL to be institutionalised, standardised and formally structured, an SL component in the curriculum is required. To plan and implement an SL module that will integrate learning in the classroom with practice in the community, it is important to conduct a needs assessment. Research has shown that educational activities based on learning needs are more effective in delivering sustainable educational outcomes for participants; therefore, a learning needs assessment should be conducted as the first step in planning an educational activity. ${ }^{[10]}$

The purpose of designing such a module in oral health would be to integrate classroom teaching with meaningful community service activities, designed as an integral feature of the clinical programme. The objectives were to explore: (i) perceptions of 2nd-year oral health students with regard to the need for a structured module for SL; and (ii) opinions of the academics at the School of Oral Health Sciences, Sefako Makgatho Health Sciences University regarding the need for an SL module.

\section{Definition of terms}

- SL is a course-based, credit-bearing educational experience in which students participate in an organised service activity that meets the identified community needs and reflect on the service activity in such a way as to gain further understanding of the course content, a broader appreciation of the discipline and an enhanced sense of personal values and civic responsibility. ${ }^{[4]}$

- Community engagement refers to the interactions and processes through which the expertise of the institution in the areas of teaching, learning and research is applied to develop and sustain society. ${ }^{[5]}$

\section{Methods \\ Study setting}

The University of Limpopos policy on community engagement (CE) identifies SL modules as one of the mandated community engagement activities. ${ }^{[1]}$ The School of Oral Health Sciences, situated in Garankuwa, Pretoria, comprises the departments of Periodontology, Oral Medicine and Community Dentistry; Maxillo-Facial Surgery, Pathology, Radiology and Orthodontics; and Restorative Dentistry, Integrated Clinical Dentistry and Prosthodontics. At the time of the study, three academic programmes were offered, i.e. Bachelor of Dental Science, Bachelor of Dental Therapy, and Diploma in Oral Hygiene. Not all the aforementioned departments, and therefore not all the academics, are involved in the teaching and training of dental therapy and oral hygiene students, as the scope of their clinical practice is limited compared with that of Bachelor of Dentistry students.

\section{Study design}

The study used an exploratory descriptive design comprising two focus group discussions with academics and students, respectively, and a quantitative survey with academics.

\section{Population and sample}

The study population for the qualitative part was selected based on their potential participation in $\mathrm{CE}$ activities. Purposive sampling was used to select the participants for the two focus group discussions. The first focus group comprised 10 3rd-year Bachelor of Dental Therapy students who had participated in unstructured CE activities during their 2nd year of study.
The second focus group comprised 11 academics who were involved in the teaching and training of the abovementioned students and served on the Curriculum Development Committee (CDC); they were therefore involved in curriculum development at the School of Oral Health Sciences, University of Limpopo Medunsa Campus (currently Sefako Makgatho Health Sciences University).

The study population for the survey comprised an additional 12 academics involved in teaching and training, who were not members of the CDC. Allinclusive sampling was used because these 12 academics were involved in the teaching and training of the abovementioned students and hence were potential implementers of the proposed SL module.

\section{Data collection method and process}

Prior to commencement of the study, ethical approval was granted by the School Research and Ethics Committee and the Medunsa Research and Ethics Committee (ref. no. MREC/E/112/2013:PG). Informed consent was obtained from participants, who were assured of confidentiality and anonymity.

The focus group discussions with the academics and students explored the participants' understanding of SL, how to structure an SL module and how to identify critical cross-field outcomes that could be attained from an SL module. In addition to these questions, in the focus group discussions the researcher also explored the students' expectations of an SL module. The focus group discussions were audio recorded, transcribed verbatim and analysed to identify emergent themes. An independent coder validated the findings for correctness after the participants had verified the accuracy of the transcribed data through member checking.

The self-developed structured questionnaire comprising three openended questions explored: (i) the academics' understanding of SL; (ii) critical cross-field outcomes; and (iii) learning outcomes that could potentially be achieved by introducing an SL module in Dental Therapy and Oral Hygiene. The frequencies were calculated in Microsoft Excel (USA) for the nine completed questionnaire received, representing a response rate of $75 \%$.

\section{Results}

The results of the survey are presented first, followed by the themes that were identified from the two focus group discussions.

\section{Survey results}

The major categories identified from the open-ended questions related to: (i) academics' understanding of SL; (ii) critical cross-field outcomes; and (iii) potential of an SL module to enhance teaching and learning.

\section{Academics' understanding of SL}

The exploration of this theme reflected that 55\% ( $n=5)$ of academics regarded SL as a 'method of teaching', while $33 \%(n=3)$ stated that SL is 'rendering service to the community'. Other responses varied from 'learning while rendering a community service' to 'combines cognitive learning with practice'.

\section{Critical cross-field outcomes}

Fig. 1 illustrates unanimity among all participants $(100 \%, n=9)$ that the following two learning outcomes could be achieved: 'identify and solve problems by using critical and creative thinking' and 'diagnose, plan and 


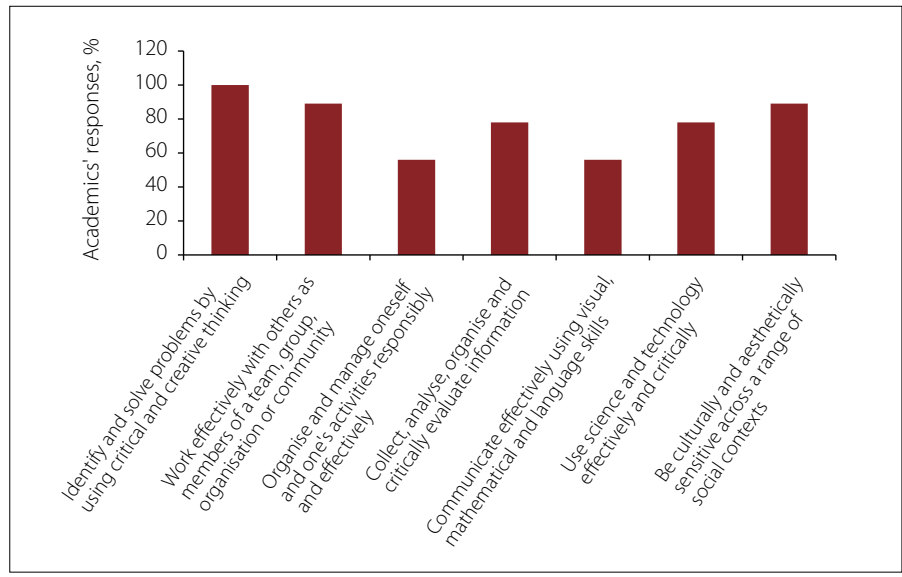

Fig. 1. Academics' responses to critical cross-field outcomes that may be achieved from an SL module.

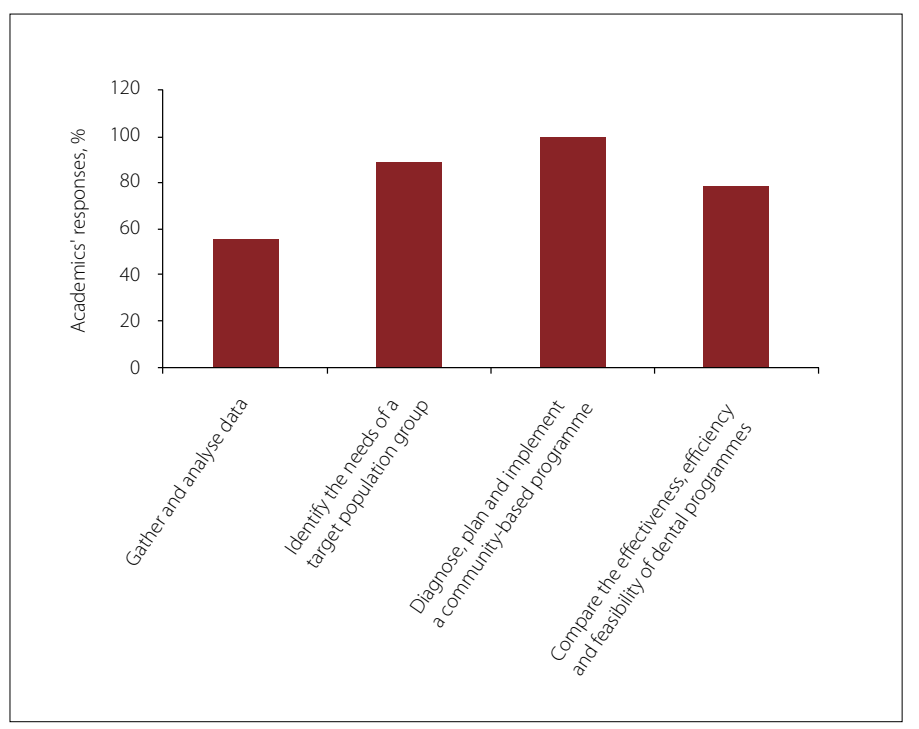

Fig. 2. Academics' responses with regard to learning outcomes that may be achieved from an SL module.

implement a community-based programme'. They further indicated that 'work effectively with others as members of a team' and developing 'cultural sensitivity' were also achievable from such an SL module $(89 \%, n=8)$. It was also mentioned that 'interacting and engaging with the community' would help students to identify the needs of a target population group $(78 \%, n=7)$.

\section{Potential of an SL module to enhance teaching and learning}

The overall responses of academics indicated that an SL module would 'enhance teaching and learning' $(89 \%, n=8)$. Responses indicated that an SL module would provide a tool for the site visit; would encourage critical thinking; and that reflection and evaluations would help students to identify strengths and weaknesses and thus enhance learning. The academics also indicated that going out into the community allows students to apply their theoretical knowledge and clinical skills in an environment that differs from the ideal conditions of training institutions. Fig. 2 summarises the academics' responses regarding learning outcomes that may be achieved from an SL module.

\section{Results emanating from the two focus group discussions}

The participants' voices are captured in Table 1. Two themes emerged from the focus groups, i.e. ( $i$ ) enhanced teaching and learning - students could apply theoretical and clinical training in an authentic setting; and (ii) standardisation of training - an SL module would ensure consistency when engaging with communities. Academic staff and students concurred that students should consult with members of the community before and after the SL activity to identify needs and expectations and obtain feedback.

\section{Enhanced teaching and learning}

The academics suggested that an SL module would 'enhance learning if structured for the reciprocity of needs. While some academics voiced the opinion that SL offers a learning experience in an authentic setting and allows students to 'look at patients as a whole', the students discussed how 'you get to see different things out there that you don't see in hospitals', which provides experience in a real-world setting and often requires students to improvise.

\section{Standardisation of training}

The students felt that an SL module would provide standardisation of training, allowing them to 'perform better', as 'we have an idea of what we are going to do'.

Students' statements, 'learning in the process of helping the community' and 'I think it's also about teaching the community', indicated that interaction with the community is a two-way learning process.

One student articulated: 'We have to know what the community needs, because different communities need different treatment.' The following observation from the student succinctly summarises the essence of SL in terms of service delivery: 'With SL there is no imposition, it's a two-way stream, we go there to learn and they receive service from us, and it's the service they want, not the service we want to give whether they want it or

Table 1. Themes and supporting statements

Enhanced teaching and learning $\quad$ Standardisation of training

'A learning experience in an 'You'll know what to do when you
authentic setting.'

'Interaction with the community is 'We have an idea of what we are a two-way learning process.' 'Consideration of community expectations.'

'You get to see different things out 'People are gonna perform better.' there that you don't see in hospitals.'

'We have to know what the needs, because different group did certain things that the communities need different treatment.'

'When we go into a community the people are actually learning, it's not just service rendering.'

'You learning in the process of helping the community.' 'It's an opportunity to see more cases.' going to do.' 'It has to be comprehensive.' group did certain things
other group didn't do.'

'People at school A are gonna benefit in a way that people at school B didn't benefit because the people at school B didn't do it.' 'Some people, they not doing things - but if it's in a course then ... ? 'So it becomes more uniformed and structured.' 
not.' The academics also agreed that community needs and expectations are often forgotten, and it is important to determine the community's values and needs from service providers. This may be achieved by obtaining feedback from the community.

They also saw great value in a multidisciplinary module that could be used by all health professionals, illustrated by the following statements: 'The best way would be an integrated module, not an oral health module', and '... a comprehensive health module that can be used throughout the Medunsa campus.'

\section{Discussion}

Although the University of Limpopo had a policy on community engagement that was approved by the Senate in 2008, all the study participants were unaware of its existence. This could explain the differences in the understanding of SL. Recommendation 33 of the HEQC report ${ }^{[12]}$ suggests that the University of Limpopo '(1) conduct an institution-wide debate on what community engagement means for the University; (2) develop a framework document that conceptualises community engagement in relation to the core functions of teaching and learning and research; and (3) put in place strategies and mechanisms to monitor and harness the impact of community engagement initiatives on the core functions of the institution'. This further indicates the need for SL to be formally embedded in the curriculum to ensure that teaching and training are in keeping with the national policy for higher education institutions and the University of Limpopo's policy on community engagement. Julie et al ${ }^{[13]}$ reported similar findings at other higher education institutions in SA.

This study indicates that SL means different things to different people. Some academics were aware that SL involves teaching students while addressing identified community needs, while others knew that SL is pedagogy in health education that combines cognitive learning with practice in the community. It is therefore imperative that academic staff are equipped and developed to provide training to students, as SL is first and foremost an academic endeavour requiring the expertise of academic staff, which provides the essential context linking community service to theoretical texts and principles. ${ }^{[1]}$

Students' understanding of SL was based on their experiences of learning in the process of visiting and helping the community. Many failed to mention the significance of reflection in providing a better understanding of the course content and the impact of social, cultural and economic factors on health. It is important to include reflection in the SL framework for dental education, as reflection is a central characteristic of SL and has been called the hyphen that links service and learning. ${ }^{[14]}$

Yoder $^{[14]}$ states that some of the most powerful learning experiences occur in a non-clinical setting, where the artificial barriers of the white coat do not interfere with communication. The responses from some academics, indicating that an SL module would provide a tool for the site visit, encourage critical thinking and thus enhance learning, validate this statement. Developing a module that incorporates SL in the oral health curriculum will allow students to apply the course content to real-world situations, which often lack the resources available at training institutions. Research has shown that courses incorporating SL components generally provide greater learning benefits than those that do not, including a deeper understanding of course material, a better understanding of the complex problems people face, and an ability to apply course material to new situations. ${ }^{[10]}$

A limitation to the results of this study should be noted. Choosing a survey for the quantitative is a limitation because the results cannot be generalised.

The findings of this study indicate that an SL component in the oral health module will enhance teaching and learning. A further study to develop a framework for the module is recommended.

\section{Conclusion}

The findings of this study indicate that an SL module would enhance teaching and learning and would impact on civic responsibility and students' retention of theoretical and practical course material. Exposure and experiences during a curriculum-integrated module would afford students the opportunity to work in a structured manner, while being guided through the dynamics of authentic settings.

Acknowledgements. The authors gratefully acknowledge the following from the University of Limpopo Medunsa Campus (currently Sefako Makgatho Health Sciences University): the CDC members and 3rd-year dental therapy students for their willingness to participate in the focus group discussions; Drs A Khan, N Nzima, and P Motloba, and Prof. T Gugushe for their assistance, and Prof. G Ogunbanjo for his feedback. The authors also acknowledge the Sub-Saharan Africa-FAIMER Regional Institute (SAFRI) for the invaluable mentorship support.

. Bender CJG, Daniels P, Lazarus J, Naude L, Sattar K. Service Learning in the Curriculum: A Resource for Higher Education Institutions. Pretoria: Council on Higher Education and Jet/CHESP, 2006:40-46.

2. Bringle RG, Hatcher JA. A service-learning curriculum for faculty. Michigan J Comm Serv Learn 1993;(2):112-122 3. Higher Education Quality Committee. Service Partnerships. Service Learning in the Curriculum: A Resource fo Higher Education Institutions. Pretoria: Council on Higher Education, 2006.

4. Hood JG. Service-learning in dental education: Meeting needs and challenges. J Dent Educ 2009;73(4):454-463.

5. Osman R, Petersen N. Students' engagement with engagement: The case of teacher education students in higher Osman R, Petersen N. Students' engagement with engagement: The case of teacher education students in higher
education in South Africa. Br J Educ Studies 2010:58(4):407-419. http://dx doi.org $/ 10.1080 / 00071005.2010 .527665$ 6. 6. Higher Education Quality Committee. Framework for Institutional Audits. Pretoria: Council on Highe Education, 2004.

. Higher Education Quality Committee. Framework for Programme Accreditation. Pretoria: Council on Higher Education, 2004.

8. Elyer J, Giles DW. Where's the Learning in Service-learning? San Francisco: Jossey-Bass, 1999.

9. Julie H, Daniels P, Adonis TA. Service-learning in nursing: Integrating student learning and community-based service experience through reflective practice. Health SA Gesondheid 2005;10(4):41-54. http://dx.doi.org/10.4102/ hsag.v10i4.206

10. Association of Reproductive Health Professionals. Conducting a CME activity needs assessment. 2002. http://arhp. org/about-us/joint-sponsorship/needs-assessment (accessed 27 January 2017).

11. University of Limpopo. Community Engagement Policy. Pretoria: UL, 2008:5. https://ulac.za/application/.. COMMUNITY\%20ENGAGEMENT\%20POLICY (accessed 3 February 2017).

12. Council on Higher Education.Higher Education Quality Committee. Report to the University of Limpopo. Executive Summary. Pretoria: CHE, 2011. http://www.che.ac.za/sites/default/files/institutional audits/institutional audits_2010_lp_executive_summary.pdfwww.che.ac.za/.../institutional_audits_2010_lp_executive_summary (accessed 3 February 2017).

13. Julie $\mathrm{H}$, Adejumo OA, Frantz JM. Cracking the nut of service-learning in nursing at a higher educational institution. Curationis 2015;38(1). http://dx.doi.org/10.4102/curationis.v3811.117

Curationis $2015 ; 38(1)$. http://dx.doi.org/ $/ 0.4102 /$ curationis.v38i1.117
4. Yoder KM. A framework for service-learning in dental education: Meeting needs and challenges. J Dent Educ 2006;70(2):115-123. 